\title{
Role and mechanism of hypoxia-inducible factor-1 in cell growth and apoptosis of breast cancer cell line MDA-MB-231
}

\author{
YONGHONG SHI ${ }^{1}$, MIAOMIAO CHANG ${ }^{1,3}$, FANG WANG $^{1}$, \\ XIAOHUI OUYANG ${ }^{2}$, YONGFENG JIA ${ }^{1}$ and HUA DU ${ }^{1}$ \\ Departments of ${ }^{1}$ Pathology, and ${ }^{2}$ Surgery, Affiliated Hospital, Inner Mongolia Medical College; \\ ${ }^{3}$ Department of Pathology, ChiFeng Hospital, Inner Mongolia Autonomous Region, P.R. China
}

Received January 26, 2010; Accepted April 21, 2010

DOI: 10.3892/ol_00000115

\begin{abstract}
The role of hypoxia-inducible factor-1 (HIF-1) in tumor development and progression is well-established but its effect on tumor growth remains controversial. The present study investigated the effect of HIF-1 on tumor growth using the estrogen receptor-negative breast cancer cell line, MDA-MB-231. Using Western blotting, we detected a higher level of HIF-1 $\alpha$ protein in MDA-MB-231 cells than in any other breast cancer cell lines analyzed, and this was accompanied by a more rapid growth pattern. Interruption of HIF-1 $\alpha$ expression using small interference RNA (siRNA) significantly suppressed cell growth and increased apoptosis, but the cell cycle was not affected. Activated fragments with increased caspase 3 activity and a mobility shift of B cell lymphoma (Bcl-2) were also detected in cells treated with HIF-1 $\alpha$ siRNA. HIF-1 allows breast cancer cells to grow under long-term serum deprivation by inactivation of the caspase cascade and thus inhibition of apoptosis. Blocking HIF-1 $\alpha$ protein resulted in loss of Bcl-2 function, which may contribute to the activation of the caspase cascade.
\end{abstract}

\section{Introduction}

Hypoxic regions within tumors frequently appear during the processes of growth and progression, resulting in the activation of hypoxia-inducible factors (HIFs). Three HIFs (HIF-1, -2 and -3) that regulate transcriptional programs in response to low oxygen level have been identified. HIF-1 was the first family member to be characterized and is composed

Correspondence to: Dr Yonghong Shi, Department of Pathology, Affiliated Hospital, Inner Mongolia Medical College, No. 1, Northern Tongdao Street, Huhhot 010050, P.R. China

E-mail: yhshi1962@yahoo.com.cn

Abbreviations: HIF-1 $\alpha$, hypoxia-inducible factor-1 $\alpha$; siRNA, small interference RNA; Bcl-2, B cell lymphoma

Key words: hypoxia-inducible factor- $1 \alpha$, cell growth, apoptosis, caspase 3 , B cell lymphoma of a $\alpha$ and $\beta$ subunit. The HIF- $1 \beta$ subunit is a constitutively expressed nuclear protein, while the HIF-1 $\alpha$ subunit is regulated by hypoxia, a variety of growth factors and cytokines, as well as tumor-modifying genes. Almost 100 target proteins were identified as being transactivated by HIF-1 and these are involved in various cellular processes including glucose uptake and metabolism, angiogenesis, erythropoiesis, cell proliferation, apoptosis and invasion $(1,2)$. Overexpression of HIF-1 $\alpha$ protein has not only been demonstrated in tumor cell lines (3) and a variety of human tumors, including bladder, breast, colon, ovarian, pancreas, prostate and kidney (4), but also correlates with poor patient outcome in a wide range of tumor types (5-7). HIF-2 was the second member of the family to be characterized and as HIF- $2 \alpha$ is structurally similar to HIF-1 $\alpha$, it heterodimerizes with the $\beta$ unit before inducing target gene expression. In contrast to HIF-1 $\alpha$, the expression of HIF- $2 \alpha$ is more restricted (8). HIF-3 is the third member of the family and its exact role has yet to be clearly defined. HIF-1 is considered to be the most important family member as it is known to be crucial for tumorigenesis (9). However, there are certain controversial, even conflicting, findings concerning its role in the modulation of tumor growth and apoptosis. Therefore, this study aimed to determine the effect of HIF-1 on tumor growth, using the human metastatic breast cancer cell line (MDA-MB-231), and to probe the underlying control mechanisms using small interfering RNA (siRNA).

\section{Materials and methods}

Cell cultures and reagents. Human breast cancer cell lines MDA-MB-231, MCF-7, MDA-MB-468, SK-BR-3 and MDA-MB-453 were obtained from the Department of Pathology, Peking University Medical Science Center, and were cultured in DMED medium or RPMI-1640 with $10 \%$ fetal bovine serum at $37^{\circ} \mathrm{C}$ in a humidified environment of $5 \% \mathrm{CO}_{2}$. Cells were subcultured in 6- or 24-well plates until $70-80 \%$ confluent. After extensive washing with phosphatebuffered saline (PBS), cells were serum-starved for various time points according to each experimental protocol. A HIF- $1 \alpha$ antibody was purchased from Sigma while antibodies against caspase 3, B cell lymphoma (Bcl-2), Bax and $\alpha$-tubulin, as well as specific secondary antibodies were purchased from the Beyotime Institute of Biotechnology. siRNA duplexes 
A

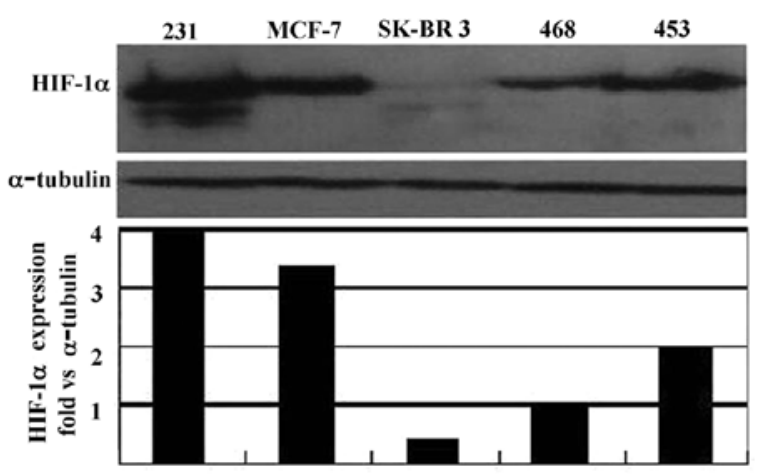

B

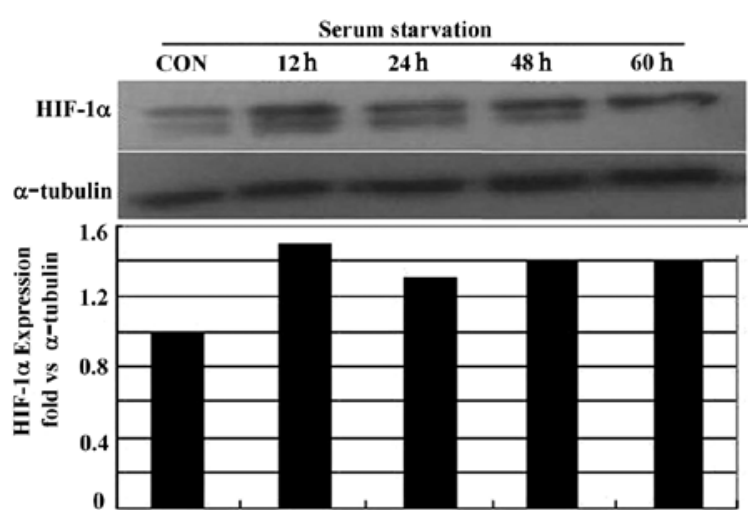

Figure 1. Expression of HIF-1 $\alpha$ protein: a number of breast cancer cell lines including MDA-MB-231, MCF-7, SK-BR-3, MDA-MB-468 and MDA-MB-453 were serum starved for (A) $24 \mathrm{~h}$ and MDA-MB-231 cells were cultured with serum as a control or serum starved for (B) $12-60 \mathrm{~h}$. Whole cell extracts were separated on $10 \%$ of SDS-PAGE and immunoblotted with HIF-1 $\alpha$ antibody. $\alpha$-tubulin was probed on the same blot to indicate equal loading. Data represent fold expression of HIF-1 $\alpha$ protein versus $\alpha$-tubulin. The results shown are representative of three independent experiments.

targeting HIF-1 $\alpha$ mRNA and transfection reagents were purchased from Santa Cruz Biotechnology.

Transfection of MDA-MB-231 cell line with hypoxiainducible factor-1 $\alpha$ small interference RNA or control small interference RNA. Cells were transfected with either siRNA duplexes targeting HIF-1 $\alpha$ mRNA (HIF-1 $\alpha$ : sense, 5-UCAAGUUGCUGGUCAUCAGdTdT-3 and antisense, 5-CUGAUGACCAGCAACUUGAdTdT-3) or with control siRNA not targeting any known genes, as previously described (10). MDA-MB-231 cells were transfected at a final siRNA duplex concentration of $80 \mathrm{pmol}$ in 6-well plates according to the manufacturer's protocol. After $6 \mathrm{~h}$ of transfection, $1 \mathrm{ml}$ of normal growth medium containing twice the normal serum and antibiotic concentration was added to the culture medium. The cells were then incubated for a further 18-24 h.

Western blotting. Following serum starvation, cells were washed with ice-cold PBS and lysed in 2\% SDS, $100 \mathrm{mM}$ DTT, $60 \mathrm{mM}$ Tris, pH 6.8. Total cell protein was quantified using the Bradford assay. Proteins were separated on 10 or $12 \%$ SDS-PAGE gels and transferred to PVDF membranes. The membranes were incubated with monoclonal antibodies against HIF-1 $\alpha$, caspase 3, Bcl-2 and Bax and specific secondary antibodies, and visualization was achieved via enhanced chemiluminescence and exposure to photographic film as previously described (11). The blot was stripped and re-probed with an antibody for $\alpha$-tubulin as an internal control.

Cell proliferation assay. MDA-231 cells (1x105/ml) expressing HIF-1 $\alpha$ or control siRNA were placed in 24 -well plates and incubated in RPMI-1640 + 10\% FCS for 9 days. Live cell numbers were regularly determined on alternate days by trypan blue staining and cell counting. Each condition was performed in quadruplicate with three counts per replicate and the average number of cells was calculated.

Flow cytometry. After appropriate treatment, cells transfected with HIF- $\alpha$ or control siRNA were stained with either propidium iodide (PI) or Annexin V-fluorescent isothiocyanate
(FITC) in combination with PI according to the manufacturer's protocol. Cell cycle status and apoptosis were then analysed by flow cytometry.

Hoechst 33258 stain. After a time period of serum starving, cells were washed twice with PBS, fixed in $4 \%$ paraformaldehyde in PBS, treated with $2 \mu \mathrm{M}$ Hoechst 33258 dye and examined under fluorescence microscopy. Cells with condensed and fragmented DNA were considered to be apoptotic.

Caspase 3 activity assay. Caspase 3 activity was determined using an assay kit (purchased from BIB) according to the manufacturer's protocol. In brief, MDA-MB-231 cells (1x105/ $\mathrm{ml}$ ) were incubated in serum-free medium, harvested in PBS and centrifuged at $500 \mathrm{~g}$ for $5 \mathrm{~min}$. The cells were lysed on ice for $10 \mathrm{~min}$ and then centrifuged at 13,000 rpm for $1 \mathrm{~min}$ at $4^{\circ} \mathrm{C}$. The supernatant was harvested and $80 \mu \mathrm{g}$ of total protein was incubated with buffer containing $10 \mathrm{mM}$ dithiothreitol and $5 \mu \mathrm{l}$ of Ac-DEVD-pNA (final concentration $200 \mu \mathrm{M}$ ) at $37^{\circ} \mathrm{C}$. The chromophore P-nitroanilide was determined at $405 \mathrm{~nm}$ with a fluorescence microplate reader.

Statistical analysis. Data were expressed as the mean \pm standard deviation (SD) and statistical analysis was performed using a Student's t-test. Results were considered significant if $\mathrm{p}<0.05$

\section{Results}

Basic expression of hypoxia-inducible factor-1 $\alpha$ protein in breast cancer cell lines. The basic expression of HIF-1 $\alpha$ protein in a number of breast cancer cell lines, with different backgrounds, including MDA-MB-231, MCF-7, MDA-MB-468, SK-BR-3 and MDA-MB-453, was assessed after $24 \mathrm{~h}$ of serum starvation. Whole cell proteins were extracted and probed by Western blotting using an anti-HIF-1 $\alpha$ monoclonal antibody. Our results showed that the MDA-MB-231 cell line expressed a higher level of HIF-1 $\alpha$ protein than any of the other cell lines tested (Fig. 1A). We also found that this cell line grew faster than other cell lines. To determine whether there was a change in HIF-1 $\alpha$ protein levels following long-term serum starvation, we cultured the cells in serum-free medium for 12-60 h. 


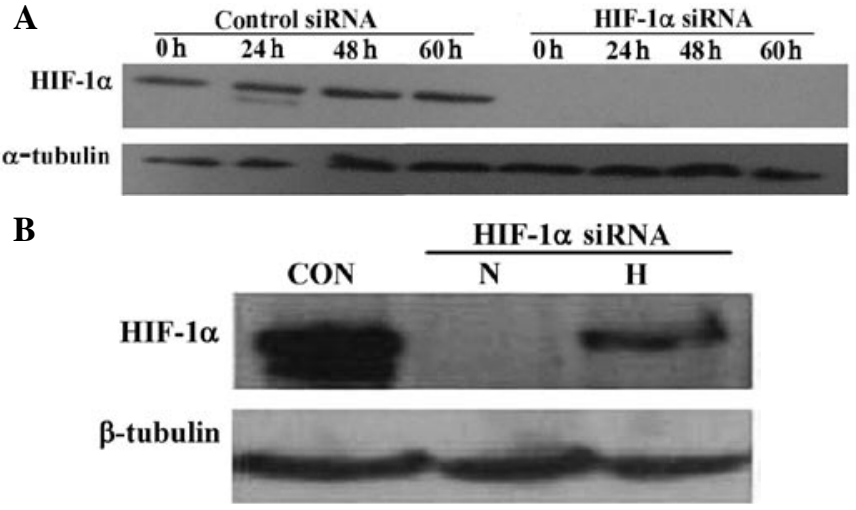

Figure 2. Blocking of HIF-1 $\alpha$ protein by siRNA. MDA-MB-231 cells were transfected with either HIF-1 $\alpha$ or control siRNA and incubated until $80 \%$ confluent. (A) After cultivation either with $(0 \mathrm{~h})$ or without serum for 24-60 h or (B) hypoxic $(\mathrm{H})$ and normoxic $(\mathrm{N})$ conditions for $6 \mathrm{~h}$, respectively. Cell protein was extracted and detected by anti-HIF- $1 \alpha$ or anti- $\alpha$-tubulin antibodies. The experiment was repeated three times.

Results showed no change in protein levels when compared to those treated with serum (Fig. 1B). This suggests that the persistent expression of HIF-1 $\alpha$ plays a key role in protecting cell growth under long-term serum deprivation.

Down-regulation of hypoxia-inducible factor-1 $\alpha$ protein by hypoxia-inducible factor-1 $\alpha$ small interference RNA. MDA-MB-231 cells were transfected with either HIF-1 $\alpha$ siRNA duplex (a HIF-1 $\alpha$ target-specific 20-25 nt siRNA designed to knock down gene expression) or a control duplex (a non-targeting 20-25 nt siRNA designed as a negative control). To examine the efficiency of HIF-1 $\alpha$ siRNA, cells were cultured in a serum-free medium for various times under normoxic conditions or for $6 \mathrm{~h}$ under hypoxic conditions. Whole cell proteins were extracted and probed by Western blotting. HIF-1 $\alpha$ protein expression was completely blocked when the transfected cells were cultured in serum or were serum-starved for 24-60 h (Fig. 2A). HIF-1 $\alpha$ was also significantly reduced under hypoxic conditions (Fig. 2B).

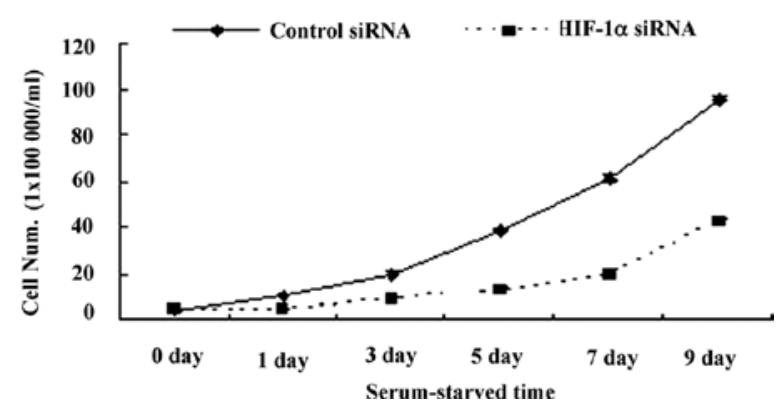

Figure 3. Effect of HIF-1 on MDA-MB-231 cell growth. MDA-231 cells $\left(1 \times 10^{5} / \mathrm{ml}\right)$ with HIF-1 $\alpha$ or control siRNA were seeded into 24 -well plates and incubated in culture medium for 9 days. Live cell numbers were counted every other day. Each condition was set in quadruplicate and three counts were performed per replicate. ${ }^{* *} \mathrm{p}<0.01$ vs. control siRNA. The experiment was repeated three times.

Role of hypoxia-inducible factor-1 $\alpha$ in cell growth under serum deprivation. To investigate the role of HIF-1 in cell growth, $1 \times 10^{5} / \mathrm{ml}$ cells transfected with either HIF-1 $\alpha$ or control siRNA were grown in 24-well plates for 9 days. Cell numbers were counted every other day and growth curves established. The results revealed that cell growth was markedly inhibited in the group with HIF-1 $\alpha$ siRNA compared to that with control siRNA (Fig. 3), suggesting a potential role for HIF-1 in protecting cell growth under serum starvation.

Effect of hypoxia-inducible factor-1 on cell cycle and apoptosis. Tumor growth depends on the number of cells proliferating (growth fraction) and the number of cells dying (cell loss). The growth fraction is calculated from the percentage of cells in the S, G2 and M phases of the cell cycle. Cell loss involves cells undergoing apoptosis and necrosis. Using flow cytometry, the cell cycle was assessed following serum starvation for varying time periods and no significant difference was found between cells treated with HIF-1 $\alpha$ siRNA and those in the control group (data not shown). Levels of apoptosis were then assessed by flow cytometry using Annexin-V FITC and PI staining. More apoptotic cells were found in the HIF-1 $\alpha$ siRNA-treated group

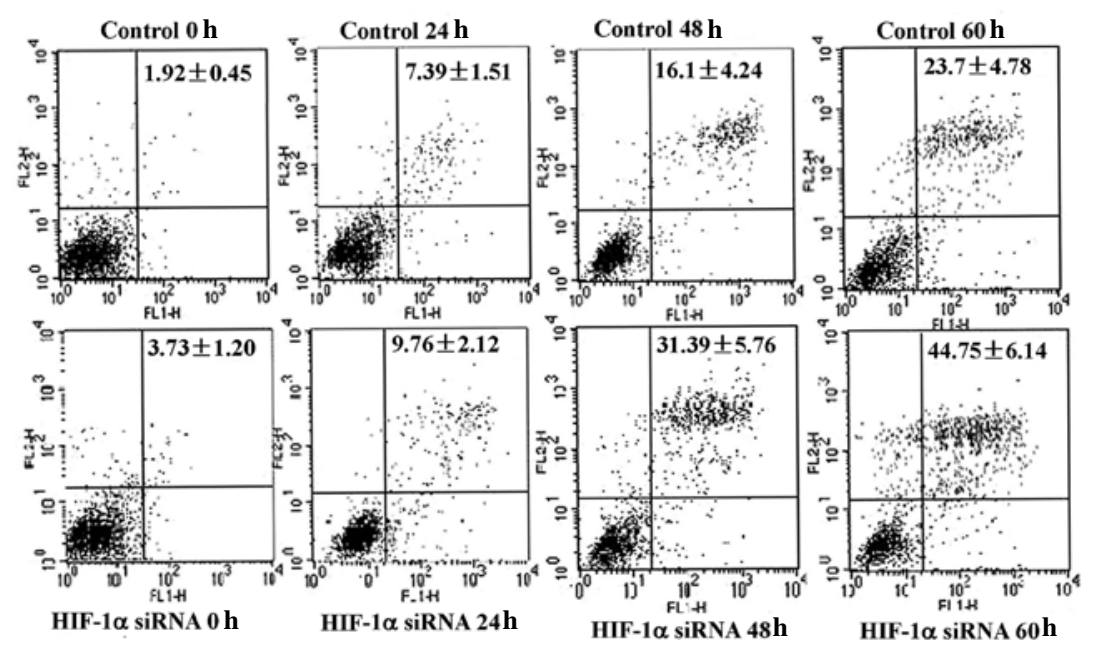

Figure 4. Effect of HIF-1 on cell apoptosis. Adherent cells $\left(1 \times 10^{5} / \mathrm{ml}\right)$ with either HIF-1 $\alpha$ or control siRNA were serum-starved for the times indicated, fixed in ethanol, stained with fluorescent isothiocyanate (FITC)-conjugated Annexin V according to the manufacturer's instructions and analyzed for apoptotic cells by flow cytometry. Membrane integrity was simultaneously assessed by PI exclusion. The percentage of apoptotic cells (Annexin V-/PI-) is shown in the upper right panel. The values shown are the mean \pm SD from three samples. ${ }^{* *} \mathrm{p}<0.01$ vs. control siRNA. Data are representative of two experiments. 
A

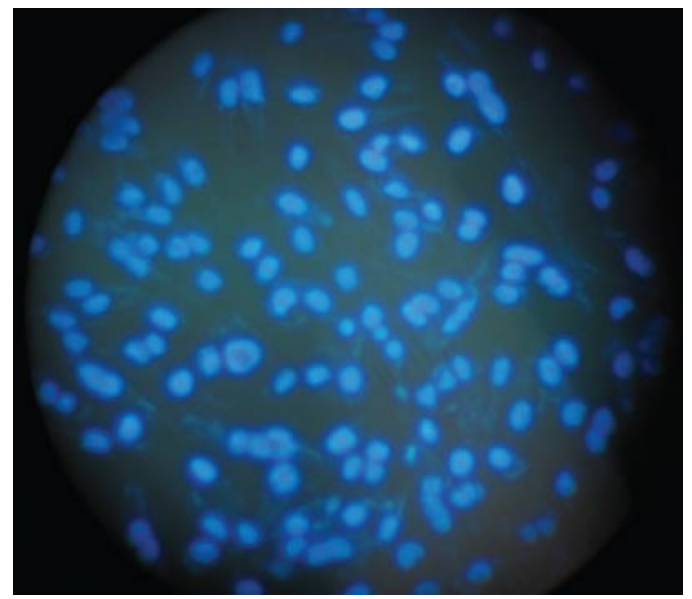

B

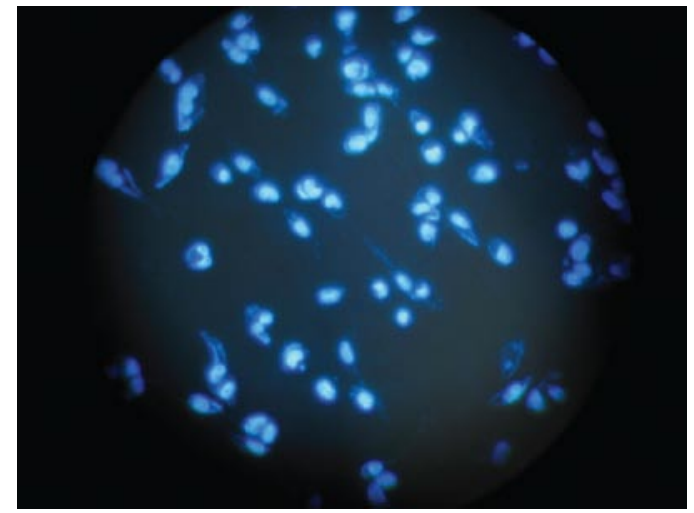

Figure 5. Apoptosis detected by Hoechst stain. After appropriate treatment cells with either control siRNA (A) or HIF-1 $\alpha$ siRNA (B) were washed twice with PBS, fixed in $4 \%$ paraformaldehyde in PBS, treated with $2 \mu \mathrm{M}$ Hoechst 33258 dye and examined under fluorescence microscopy. The experiment was repeated twice with representative data from the $48 \mathrm{~h}$ time point shown.

compared with the controls and this difference was significant after $48 \mathrm{~h}$ (Fig. 4). Furthermore, when the HIF-1 $\alpha$ siRNAtreated cells were stained with Hoechst 33258 (Fig. 5A and B), more condensation or fragmentation of DNA was noted. This result morphologically confirmed the flow cytometry results. The results therefore suggest that HIF-1 promotes cell growth under serum deprivation by protecting cells from apoptosis rather than by shifting the cell cycle from G0-G1 to G2-S.

Anti-apoptosis of hypoxia-inducible factor-1: Involvement of caspase cascade and B cell lymphoma. The caspase cascade is a typical pathway for the initiation of apoptosis and $\mathrm{Bcl}-2$ is a key modulating factor in this cascade. In order to determine the anti-apoptotic role of HIF-1 cells, with either HIF-1 $\alpha$ or control siRNA, were serum-starved for various times and protein extracts were probed with anti-caspase 3, Bcl-2 and Bax antibodies. The anti-caspase 3 antibody can detect procaspase $3(35 \mathrm{kDa})$ and its activated fragments (molecular weight 17 and $12 \mathrm{kDa}$ ). Our results showed that levels of procaspase $3 \mathrm{did}$ not change in either of the treatment groups. However, in the HIF-1 $\alpha$ siRNA-treated group, the activated fragment $(17 \mathrm{kDa})$ was present in all samples from 0-48 $\mathrm{h}$ of serum starvation and a weak expression of the $12 \mathrm{kDa}$ fragment was noted at $48 \mathrm{~h}$. In contrast, the activated fragment $(17 \mathrm{kDa})$ was only detected after $48 \mathrm{~h}$ of serum starvation in the control siRNA group (Fig. 6A). Increased

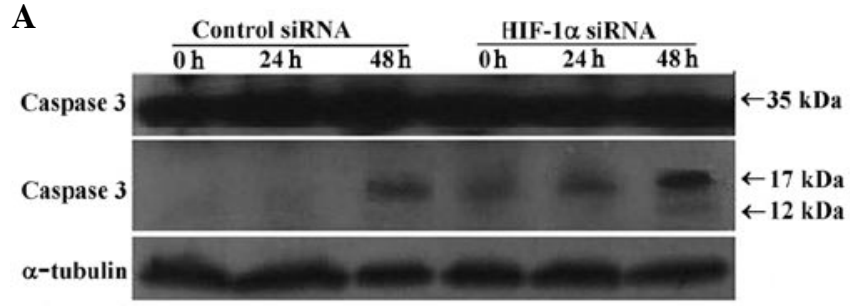

B
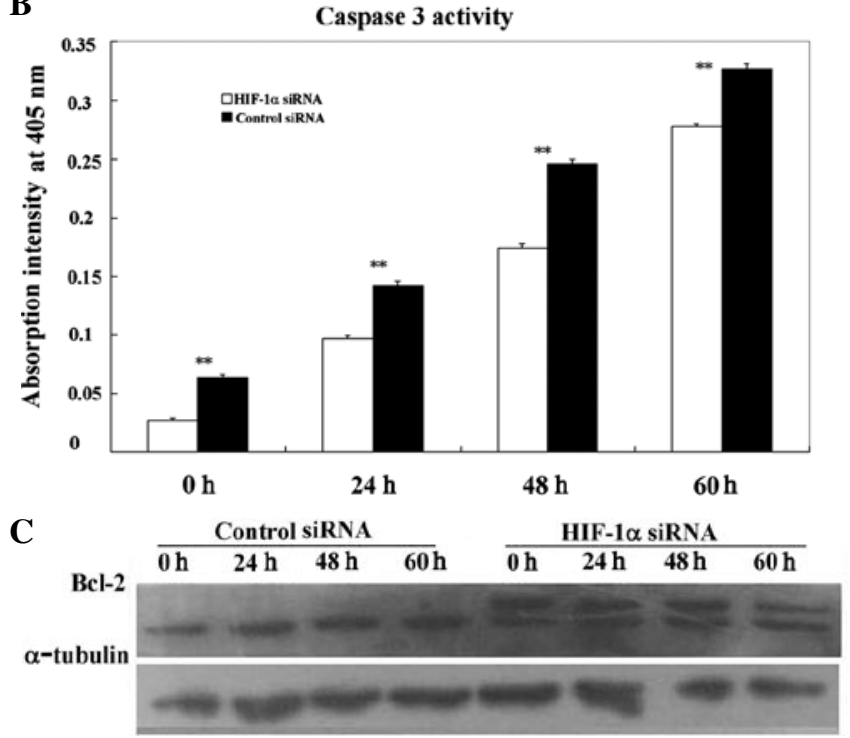

Figure 6. Activation of capsase 3 and phosphorylation of Bcl-2 after loss of HIF-1. After serum starvation for different times, whole cell proteins were probed with antibodies against caspase 3 or Bcl-2 by immunoblotting. (A) The anti-caspase 3 antibody detected activated fragments of 17 and $12 \mathrm{kDa}$ and (C) the Bcl-2 antibody detected an alternatively-sized band in cells treated with HIF-1 $\alpha$ siRNA, although this band was not observed in cells treated with control siRNA. Cell pellets were collected, lysed on ice and centrifuged. The supernatant protein was incubated with buffer containing dithiothreitol and Ac-DEVD-pNA. (B) Caspase 3 activity was determined at $405 \mathrm{~nm}$ with a fluorescence microplate reader.

caspase 3 activity was observed at all time points $(0-60 \mathrm{~h}$ of serum starvation) following transfection with HIF- $1 \alpha$ siRNA when compared to the control group (Fig. 6B). This observation was in-line with the detection of activated caspase 3 fragments by Western blotting and suggests a role for HIF-1 in the inactivation of the caspase cascade. Bcl-2 and Bax are two members of the Bcl-2 family that play contradictory roles in the regulation of apoptosis. Our results showed no change in the Bax protein expression (data not shown). However, the expression of Bcl-2 (28 kDa molecular weight) was detected in cells transfected with either HIF-1 $\alpha$ or control siRNA and, notably, a larger band was also detected in cells transfected with HIF-1 $\alpha$ siRNA (Fig. 6C). This larger band may be due to multiple site phosphorylation of Bcl-2, which would result in an increase in molecular weight and may be related to the loss of HIF-1 followed by apoptosis.

\section{Discussion}

HIF-1 is crucial for tumor progression involving growth, invasion and metastasis (12).

Tumor cells adapt to a lack of oxygen and nutrients, continue to grow and escape necrosis and apoptosis. Previous 
studies suggested that HIF-1 promotes tumor growth or suppresses apoptosis (13-15). However, other studies found that HIF-1 inhibited tumor growth and promoted hypoxia-induced apoptosis $(16,17)$. Bafilomycin A1, a potential anticancer agent, was also found to restrict cell proliferation and tumor growth by inhibiting the degradation of the HIF-1 $\alpha$ protein (18). A further study using a three-dimensional model found that HIF-1 promoted hepatoma cell growth, but that a HIF-1 deficient counterpart showed increased proliferation and a higher rate of apoptosis than a wild-type hepatoma (19). Since tumor growth depends on the balance between the growth fraction and cell loss (necrosis and apoptosis, respectively), our study aimed to determine the role of HIF-1 in tumor growth and the possible mechanisms involved.

Detection of the basic expression of HIF-1 $\alpha$ protein in a number of breast cancer cell lines provided further evidence for the universal expression of HIF-1 $\alpha$ protein in tumor cells (3). MDA-MB-231, a metastatic breast cancer cell line showed a relatively higher level of HIF-1 $\alpha$ protein compared to other cell lines analyzed, implying a possible correlation between HIF-1 expression and a malignant phenotype. Sustained growth with the expression of HIF-1 $\alpha$ protein under long-term serum starvation suggested a potential relationship between HIF-1 and cell growth. Blocking the expression of HIF-1 $\alpha$ using siRNA down-regulated cell growth confirmed previous studies indicating that suppression of HIF-1 decreases cell proliferation in vitro (13-15,20-22). Our study not only confirmed the role of HIF-1 in promoting growth, but also showed that apoptotic inhibition, as opposed to a shift in the cell cycle from G0 to G1, contributed to the role of HIF-1 in cell growth.

Apoptosis is triggered by a variety of factors such as death receptors, stress (including serum deprivation and growth factor depletion), free radicals, ionizing radiation, and factors released from cytotoxic $\mathrm{T}$ cells. Under stress, cytochrome $\mathrm{C}$ released an apoptotic inhibitor from the mitochondrial interaction with Apaf-1 resulting in the recruitment of procaspase 9, which activates caspase cascades. The effector caspases 3, 6 and 7, are downstream of the activator caspases and cleave various targets leading to apoptosis. Precursor caspase 3, a $35-\mathrm{kDa}$ protein, is cleaved into 17 and $12 \mathrm{kDa}$ fragments following activation (23). When HIF-1 $\alpha$ protein was blocked we detected an activated fragment of caspase $3(17 \mathrm{kDa})$ from 0-48 h serum starvation. A $12 \mathrm{kDa}$ fragment was also faintly detected after $48 \mathrm{~h}$ of starvation. These findings demonstrate that the interruption of HIF-1 promotes cell apoptosis by activating the caspase cascade.

The Bcl-2 family comprises a number of members of which Bad, Bid, Bax, Bim and Bik are pro-apoptotic proteins while Bcl-2 and Bcl-xL are anti-apoptotic proteins (24). Pro-apoptotic members promote the release of cytochrome $\mathrm{C}$ from mitochondria in response to stress factors, while anti-apoptotic members inhibit this process (25). A number of studies showed that Bcl-2 undergoes multiple phosphorylations $(26,27)$ resulting in a molecular mobility shift of the Bcl-2 protein and loss of anti-apoptotic function $(27,28)$. Consistent with these studies, we also noticed a molecular mobility shift of the Bcl-2 protein in the HIF-1 $\alpha$ siRNA group, but not in the control group, suggesting that loss of HIF-1 results in the phosphorylation of Bcl-2 followed by loss of its anti-apoptotic function, resulting in the release of cytochrome $\mathrm{C}$ from mitochondria and further activation of the caspase cascade. Our study has therefore shown that HIF-1 protects cell growth under serum-deprived conditions via the inhibition of apoptosis.

\section{Acknowledgements}

We would like to thank Dr Lynne Bingle for editorial assistance with the manuscript. This study was supported by the National Natural Science Foundation of China (30560057 and 30860331), The Inner Mongolia Natural Science Foundation (200508010911) and the Key Project of the Science and Technology Inner Mongolia Medical College (NY2004ZD001).

\section{References}

1. Semenza GL: HIF-1 and mechanisms of hypoxia sensing. Curr Opin Cell Biol 13: 167-171, 2001.

2. Volm M and Koomagi R: Hypoxia-inducible factor (HIF-1) and its relationship to apoptosis and proliferation in lung cancer. Anticancer Res 20: 1527-1533, 2000.

3. Zhong H, Mabjeesh N, Willard M and Simons J: Nuclear expression of hypoxia-inducible factor 1alpha protein is heterogeneous in human malignant cells under normoxic conditions. Cancer Lett 181: 233-238, 2002.

4. Jubb AM, Pham TQ, Hanby AM, et al: Expression of vascular endothelial growth factor, hypoxia inducible factor 1alpha, and carbonic anhydrase IX in human tumours. J Clin Pathol 57: 504-512, 2004.

5. Osada R, Horiuchi A, Kikuchi N, Yoshida J, Hayashi A and Ota M: Expression of hypoxia-inducible factor 1alpha, hypoxiainducible factor 2alpha, and von Hippel-Lindau protein in epithelial ovarian neoplasms and allelic loss of von HippelLindau gene: nuclear expression of hypoxia-inducible factor 1alpha is an independent prognostic factor in ovarian carcinoma. Hum Pathol 38: 1310-1320, 2007.

6. Yoshimura H, Dhar DK, Kohno H, et al: Prognostic impact of hypoxia-inducible factors 1 alpha\} and 2 alpha\} in colorectal cancer patients: correlation with tumor angiogenesis and cyclooxygenase-2 expression. Clin Cancer Res 10: 8554-8560, 2004.

7. Kubo T, Sugita T, Shimose S, Matsuo T, Arihiro K and Ochi M: Expression of hypoxia-inducible factor-1\{alpha\} and its relationship to tumour angiogenesis and cell proliferation in cartilage tumours. J Bone Joint Surg Br 90B: 364-370, 2008.

8. Wiesener MS, Jurgensen JS, Rosenberger C, et al: Widespread, hypoxia-inducible expression of HIF-2alpha in distinct cell populations of different organs. FASEB J 17: 271-273, 2003.

9. Rankin EB and Giaccia AJ: The role of hypoxia-inducible factors in tumorigenesis. Cell Death Differ 15: 678-685, 2008.

10. Ameri K, Lewis CE, Raida M, Sowter H, Hai T and Harris AL: Anoxic induction of ATF-4 through HIF-1-independent pathways of protein stabilization in human cancer cells. Blood 103: 1876-1882, 2004.

11. Shi YH, Wang YX, Bingle L, et al: In vitro study of HIF-1 activation and VEGF release by bFGF in the T47D breast cancer cell line under normoxic conditions: involvement of PI-3K/Akt and MEK1/ERK pathways. J Pathol 205: 530-536, 2005.

12. Zagzag D, Zhong H, Scalzitti JM, Laughner E, Simons JW and Semenza GL: Expression of hypoxia-inducible factor 1 alpha in brain tumors - association with angiogenesis, invasion, and progression. Cancer 88: 2606-2618, 2000.

13. Gillespie DL, Zhong H, Scalzitti JM, Laughner E, Simons JW and Semenza GL: Silencing of hypoxia inducible factor-1alpha by RNA interference attenuates human glioma cell growth in vivo. Clin Cancer Res 15: 2441-2448, 2007.

14. Kilic M, Kasperczyk H, Fulda S and Debatin KM: Role of hypoxia inducible factor-1 alpha in modulation of apoptosis resistance. Oncogene 26: 2027-2038, 2007.

15. Zhang X, Kon T, Wang $\mathrm{H}$, et al: Enhancement of hypoxiainduced tumor cell death in vitro and radiation therapy in vivo by use of small interfering RNA targeted to hypoxia-inducible factor-1\{alpha\}. Cancer Res 64: 8139-8142, 2004. 
16. Krick S, Eul BG, Hanze J, et al: Role of hypoxia-inducible factor-1 1 alpha\} in hypoxia-induced apoptosis of primary alveolar epithelial type II cells. Cell Mol Biol 32: 395-403, 2005.

17. Mack FA, Rathmell WK, Arsham AM, Gnarra J, Keith B and Simon MC: Loss of pVHL is sufficient to cause HIF dysregulation in primary cells but does not promote tumor growth. Cancer Cell 3: 75-88, 2003.

18. Lim JH, Park JW, Kim MS, Park SK, Johnson RS and Chun YS: Bafilomycin induces the p21-mediated growth inhibition of cancer cells under hypoxic conditions by expressing hypoxiainducible factor-1\{alpha\}. Mol Pharmacol 70: 1856-1865, 2006.

19. Emerling BM, Platanias LC, Black E, et al: Mitochondrial reactive oxygen species activation of $\mathrm{p} 38$ mitogen-activated protein kinase is required for hypoxia signaling. Mol Cell Biol 25: 4853-4862, 2005 .

20. Yoshida D, Kim K, Noha M and Teramoto A: Anti-apoptotic action by hypoxia inducible factor 1-alpha in human pituitary adenoma cell line, HP-75 in hypoxic condition. J Neurooncol 78: 217-225, 2006

21. Takahashi $Y$, Nishikawa M and Takakura Y: Inhibition of tumor cell growth in the liver by RNA interference-mediated suppression of HIF-1alpha expression in tumor cells and hepatocytes. Gene Ther 15: 572-582, 2008.

22. Song Y, Wang W, Qu X and Sun S: Effects of hypoxia inducible factor-1alpha (HIF-1alpha) on the growth and adhesion in tongue squamous cell carcinoma cells. Indian J Med Res 129: 154-163, 2009.
23. Yang JY, Walicki J, Michod D, Dubuis G and Widmann C: Impaired akt activity down-modulation, caspase-3 activation, and apoptosis in cells expressing a caspase-resistant mutant of RasGAP at position 157. Mol Biol Cell 16: 3511-3520, 2005.

24. Wei MC, Zong WX, Cheng EH, et al: Proapoptotic BAX and BAK: a requisite gateway to mitochondrial dysfunction and death. Science 292: 727-730, 2001.

25. Scorrano L and Korsmeyer SJ: Mechanisms of cytochrome c release by proapoptotic BCL-2 family members. Biochem Biophys Res Commun 304: 437-444, 2003.

26. Amamoto $\mathrm{K}$, Ichijo $\mathrm{H}$ and Korsmeyer SJ: BCL-2 is phosphorylated and inactivated by an ASK1/Jun N-Terminal protein kinase pathway normally activated at G2/M. Mol Cell Biol 19: 8469-8478, 1999.

27. Kondo E, Ichijo H and Korsmeyer SJ: Expression of phosphorylated Ser70 of Bcl-2 correlates with malignancy in human colorectal neoplasms. Clin Cancer Res 11: 7255-7263, 2005.

28. Blagosklonny MV, Schulte T, Nguyen P, Trepel J and Neckers LM: Taxol-induced apoptosis and phosphorylation of Bcl-2 protein involves c-Raf- 1 and represents a novel c-Raf-1 signal transduction pathway. Cancer Res 56: 1851-1854, 1996. 